\title{
¿MOVILIDAD SOCIAL ASCENDENTE EN LOS INDIGENAS URBANOS CONTEMPORÁNEOS? DON, MERCADO E INSERCIÓN SOCIAL ENTRE LOS MIXTECOS DE CIUDAD DE MÉXICO
}

\author{
SOCIAL ASCENDING MOBILITY IN THE URBAN \\ CONTEMPORARY ABORIGENS? GIFT, MARKET AND SOCIAL \\ INSERTION AMONG THE MIXTECOS OF MÉXICO CITY
}

\section{NICOLÂS GISSI B. ${ }^{1}$}

\section{RESUMEN}

El presente artículo tiene como propósito analizar los sistemas de integración social de la población mixteca en la Ciudad de México. Los inmigrantes mixtecos (y sus hijos nacidos en la ciudad), provenientes desde el estado de Oaxaca, se han reubicado en la periférica colonia San Miguel Teotongo, constituyendo enclaves étnicos. Desde la década de los setenta han luchado por el derecho a la ciudad participando de la Unión de Colonos local, al mismo tiempo que manteniendo su red étnica. Asimismo, se han adaptado a la "terciarización" de la economía mundial a través de instalar negocios en sus propias viviendas, pasando de empleados a autoempleados.

Palabras clave: Mixtecos, intercambios económicos, enclaves étnicos, integración social, Ciudad de México.

\section{ABSTRACT}

The purpose of this paper is to analyze the systems of social integration of the population Mixteca in the Mé

xico City. Coming from the Mixteca region in Oaxaca's state, they have re-settled themselves in the peripheral colony San Miguel Teotongo, establishing ethnic enclaves. Holding their ethnic network, the Mixtecos immigrants (and their children born in the city) have struggled for their right to the city. They have also adapted to the world neoliberal economy creating stores in their own homes, shifting from an employed to a self-employed status.

Keywords: Mixtecos, economic exchanges, ethnic enclaves, social integration, Mexico City.

Recibido: 30.09.10. Aceptado: 06.01.11.

${ }^{1}$ Antropólogo, profesor del Departamento de Sociología y Antropología, Universidad de Concepción. Concepción, Chile. E-mail: ngissi@udec.cl 


\section{INTRODUCCIÓN}

$\mathrm{D}$

ESDE LAS DOS ÚLTIMAS décadas del siglo XX la antropología social latinoamericana ha reconocido e investigado un "nuevo" sujeto residente en nuestras ciudades, y especialmente en las metrópolis: los indígenas urbanos. En México, las tempranas indagaciones de Butterworth (1962, 1971), Arizpe (1975) y Kemper (1976), así como los posteriores estudios de Hirabayashi (1984), Oehmichen (2005), Molina y Hernández (2006) y Martínez (2007), entre otros, desde principios de los años sesenta -e incluso antes, con la pionera obra de Pozas (1948)-, hasta nuestros días, han develado la persistencia de las identidades étnicas en los habitantes indígenas de las ciudades y megalópolis. Pensar que una persona perteneciente a un pueblo indígena pierde su adscripción étnica por haber nacido fuera de las comunidades campesinas o poblados rurales sería por lo demás reducir/esencializar a los indígenas como campesinos o habitantes rurales, no observándose/reconociéndose la dinámica empírica que nos revela una permanente interacción e intercambio entre la población residente en las urbes y los familiares que permanecen en el campo, así como (en el caso del pueblo mixteco, que aquí analizaremos) con quienes habitan en las distintas ciudades de los Estados Unidos.

Tales textos han concordado, más allá de las particularidades étnicas y nacionales, en que los sujetos indígenas suelen compartir la identidad de clase con el sector pobre de las urbes, pero que al mismo tiempo se diferencian de tal población por la acentuación de la discriminación del "otro" -los mestizos- que, sumada a la de clase, sobrepone la étnica. Sin embargo, aún quedan muchas interrogantes sobre la población indígena residente en las urbes mexicanas y en particular respecto a quienes viven en Ciudad de México $^{2}$, varias de las cuales se refieren a las relaciones de la población indígena con el Estado y el mercado, así como a las dinámicas sociales en el espacio urbano.

La pregunta general planteada en estas páginas se cuestiona: ¿cómo los mixtecos (o Nuu Savi en lengua mixteca) de la colonia San Miguel Teotongo $^{3}$ se insertan/integran socio-económicamente hoy en día a la Ciudad de

${ }^{2}$ La Ciudad de México se inserta en la Zona Metropolitana de Ciudad de México (ZMCM), la que está conformada por 16 delegaciones políticas que constituyen el Distrito Federal (D.F.), además de 37 municipios conurbados del Estado de México y uno del estado de Hidalgo, contando con una población total de 17.884.829 habitantes (Censo, 2000).

${ }^{3} \mathrm{La}$ actual colonia (comuna) San Miguel Teotongo se encuentra al este de la delegación Iztapalapa. Al ser una zona al margen de los proyectos de planificación urbana, en este territorio na- 
México y a la sociedad nacional en el contexto económico global de la "reforma estructural" neoliberal?, problema que se articula por medio de las siguientes preguntas iniciales: ¿qué tipos de intercambios socioeconómicos predominan actualmente en las interacciones intra e interétnicas? ¿De qué manera los mixtecos se vinculan (como individuos y como grupo etnolingüístico) con los organismos estatales mexicanos? ¿Cómo participan en el sistema de mercado? Las respuestas a tales inquietudes se abordaron a partir de modelos teóricos propios de la antropología económica y urbana, y metodológicamente a través del trabajo de campo etnográfico, buscando una comprensión tanto transversal como longitudinal de la integración a la gran ciudad del grupo étnico mixteco.

El presente texto tiene como objetivo, entonces, conocer las formas de inserción e integración socioeconómica de la población indígena en la multiétnica colonia San Miguel Teotongo, ubicada en la Delegación Iztapalapa $^{4}$. Específicamente se busca indagar en las modalidades actuales de intercambio material de la población originaria de la región mixteca oaxaqueña: inmigrantes del grupo etnolingüístico ñuu savi, así como nacida en la Ciudad de México (la denominada "segunda generación"), en el contexto económico-político mundial de declive de la industrialización y de la "sociedad salarial", asumiendo como referencia histórica el origen de la colonia, en los inicios de la década de 1970.

De este modo, entiendo que, si bien la población mixteca ${ }^{5}$ está inserta/ integrada (en mayor o menor grado, sea de manera formal o informal) a los mercados de trabajo, insumos y crédito, al mismo tiempo mantiene un componente no capitalista y no monetario indispensable para su reproducción social, inmersa en una racionalidad que combina criterios de mercado con estrategias de sobrevivencia, que por lo general se sostienen

tural (un cerro/volcán) y periférico se encontraban -a principios de 1970- terrenos relativamente accesibles, lo que atrajo a moradores jóvenes, en su mayoría inmigrantes del sur del país. Año a año se empezó a equipar con viviendas autoconstruidas, pavimentación de caminos, pequeñas tiendas y cocinas económicas de tipo familiar. Enfrentados con la urgencia de actuar, se formó desde los inicios la Unión de Colonos San Miguel Teotongo (UCSMT), la que aglutinó a la mayoría de los vecinos.

${ }^{4}$ Iztapalapa es actualmente la delegación del Distrito Federal con mayor presencia de población indígena, con 86.813 hablantes de lengua indígena, representando el 4,9\% de la población total de esta delegación. De este modo, ocupa el tercer lugar respecto a porcentajes de población indígena en sus respectivas delegaciones, solo después de Milpa Alta, con un 11,5\% y Xochimilco, con un 5,9\% (INI-CONAPO, 2000).

${ }^{5}$ De acuerdo a la Comisión Nacional para el Desarrollo de los Pueblos Indígenas (CDI, 2000) la población total mixteca en México (distribuida entre diversos estados) es de 726.601 personas, representando la cuarta mayor población indígena a nivel nacional, después de la náhuatl, maya y zapoteca. 
en relaciones de confianza entre "paisanos". Entre las estrategias (comunitarias y familiares) de sobrevivencia y los mecanismos de mercado se vive cotidianamente un continuum de diversas prácticas socioeconómicas.

La hipótesis de trabajo que guía la investigación afirma que los inmigrantes mixtecos suelen desarrollar, en la Ciudad de México, estrategias/ tácticas colectivas y familiares en búsqueda de una mayor inserción en la sociedad mexicana, participando en asociaciones y redes sociales horizontales y verticales basadas en la confianza y reciprocidad, tendiendo a la concentración residencial y ocupacional en determinados barrios y calles de la colonia en estudio. A partir de estos apoyos mutuos consiguen integrarse en empleos, tanto en el sector informal como formal, principalmente a través del comercio, participando en los intercambios de mercado monetarizado así como vinculándose, por medio de las organizaciones, con las instituciones estatales. Estos recursos/activos se transmiten a los nacidos en la ciudad, quienes tenderían a lograr mayores grados de educación y de trabajos formales.

En las siguientes páginas expongo el marco referencial que me ha permitido explorar, describir y comprender la temática en estudio. Al centrarse la observación antropológica en los vínculos entre sujetos (esto es, visualizando la sociedad como una red o un conjunto de redes yuxtapuestas), y no en los individuos como entes separados, el modelo teórico del intercambio social y el enfoque de la exclusión social resultan relevantes ejes de análisis para comprender los procesos de exclusión/inserción/integración económica de los miembros de grupos étnicos en la sociedad nacional. Vinculo ambos modelos, pues sostengo que la integración social implica participar en los intercambios sociales, en la convivencia, en los circuitos de cooperación. Inversamente, la exclusión social se refiere a la falta de acceso, de vínculos, de comunicación (y por ende de información).

\section{LOS INTERCAMBIOS ECONÓMICOS Y LA INTEGRACIÓN SOCIAL EN LOS ESTUDIOS ANTROPOLÓGICOS}

Presento aquí sintéticamente lo que podemos reconocer como el modelo antropológico del intercambio social. Este constructo teórico, de acuerdo a C. Lomnitz:

es quizás la principal contribución de la antropología al pensamiento social, [suscitó] un prolongado examen de los significados y las formas del intercambio, así como de sus implicaciones para el orden social, la 
producción de cultura y de valor, la política, e incluso para la comprensión de las condiciones del conocimiento propio de las ciencias sociales (2005: 312-313).

Uno de los primeros científicos sociales que se refirió a la importancia sociológica del intercambio económico a través de estudios etnográficos fue B. Malinowski. En 1922, se publica Los argonautas del Pacífico Occidental, texto de Malinowski que suele considerarse como el primer estudio de antropología económica moderna. En esta obra coloca la ceremonia isleña del kula en el contexto de una totalidad cultural, relacionándolo con las creencias trobriandesas, su sistema de parentesco, estructura política y sistema económico. El kula es una modalidad de intercambio económico melanesio, de forma circular, en el que existen dos esferas de interacción paralelas: una en la que se intercambian alimentos y objetos comunes, y otra en la que se intercambian joyas (collares y brazaletes), objetos valiosos, reforzándose a través de éstos las relaciones sociales y de poder. En el intercambio de objetos de valor práctico o comercial se observa un intenso regateo, comportamiento que no ocurre en la ceremonia formal del kula.

De este modo, Malinowski identificó siete tipos distintos de intercambios extendidos sobre una dimensión continua de interés. En un polo estaría el "don puro", en el que el cálculo es nulo, y en el extremo opuesto se encontraría el "simple comercio", en que el interés es total. Entre ambos polos estarían los cinco tipos de intercambios restantes. A cada tipo corresponde una relación distinta entre las personas que intercambian. Así, el primero supone una relación íntima (polo social) y el último una relación de desconocimiento (polo económico).

Unos años después, en el Ensayo sobre el don (1925), Mauss explicó a partir de los relatos de Malinowski (1922; como de Boas, 1899) y específicamente a través del kula, el papel del intercambio en la emergencia de las sociedades. Mauss señala que el hecho del don es compartir voluntariamente lo que se tiene o lo que se es (o más bien: lo que se es a partir de lo que se tiene). Es a la vez un acto en que se instaura una relación doble entre el donador y el receptor. Este regalo -advierte el autor-crea una deuda en quien lo recibe, esto es, genera la obligación de devolver (la "lógica del don" genera un entramado social a través de cotidianos actos de dar-recibir-devolver). De este modo, Mauss destaca el carácter paradójico del don: es por definición voluntario, y por ello gratuito; sin embargo, todas las sociedades obligan (implícitamente) a los individuos a practicar el intercambio.

Inclusive, el no hacer el contra-don suele generar la cara del don en negativo, la del daño, en la medida que se cristaliza el malestar/odio resul- 
tante de una interrupción de los flujos de generosidad. La brujería -por ejemplo- es una forma de guerra a distancia, invisible, como una venganza, que se sitúa en el extremo opuesto de la magia positiva, la que genera una lógica de juego cooperativo. Como señala Godbout, "instaura, en efecto [la brujería] un juego de suma nula, que desintegra y hace morir" (1997: 171). Analizando la obra de Mauss, y el hecho de la hostilidad o violencia potencial en los intercambios, Lévi-Strauss afirma en Las estructuras elementales del parentesco:

el juego sabio de los intercambios [...] consiste en un conjunto complejo de maniobras, conscientes o inconscientes, para ganar seguridades y precaverse contra riesgos, en el doble terreno de las alianzas y de las rivalidades [...] los intercambios son guerras resueltas en forma pacífica; las guerras son el resultado de transacciones desafortunadas (1969: 93 y 107).

Entonces, el alimento, las propiedades, los rangos, la magia, los favores, todo sería materia de don y contra-don. Estos fenómenos son ejemplos de una forma "arcaica" de cambio en la que se da una circulación de los objetos junto a una circulación de las personas.

El otro ejemplo etnográfico fundamental es el brindado por Boas (1899) respecto al potlatch de los kwakiutl de la costa noroeste de los Estados Unidos. Éste es conocido como la distribución formal de dones por parte del jefe de los anfitriones a sus huéspedes, precedido por un acto festivo, con objeto de anunciar un cambio individual de estatus. Cuando dos individuos tenían iguales derechos para heredar el mismo título, entraban en competencia. La estrategia consistía en dar más que el rival o más de lo que el rival pudiera devolver. Se buscaba la ayuda de los parientes y aliados para acumular la riqueza (Godelier, 1981: 95-96). Estas competencias que Mauss (1925) denomina como "prestaciones totales de tipo agonístico" reordenaban la jerarquía social en beneficio de los más generosos. Son "hechos sociales totales" (Mauss, ibid) pues se refieren a bienes y servicios materiales (dimensión económica), reorganizan las autoridades (dimensión política), y refuerzan los valores de reciprocidad, de honor y generosidad (dimensión moral); y son "prestaciones agonísticas" (del griego agon: luchar, combatir) pues los jefes-socios están implicados en una rivalidad.

Ahora bien, Godelier (1998) destacó -entre otros puntos- en su obra El enigma del don, que Mauss había percibido la existencia de dos esferas de riquezas, la de los bienes alienables o las cosas que se pueden donar, y la de los bienes inalienables, o que deben guardarse. Estos bienes pro- 
tegidos (objetos preciosos, talismanes, saberes, ritos, etc.) al transmitirse generacionalmente afirman una serie de identidades y su continuidad en el tiempo. Tales bienes singularizados sostendrían diferencias de identidad no sólo entre sociedades, sino también entre sus grupos e individuos de una misma sociedad.

El texto de P. Bohannan (1962) sobre los tiv de Nigeria Central complementa estos análisis destacando distintas esferas de intercambio en lo que constituye una descripción clásica de una "economía multicéntrica". En este grupo étnico se reconocía la existencia de dos esferas principales: la del don y contra-don, en la que es incorrecto llevar a cabo cálculos de valor, y la del mercado, donde se truecan valores de intercambio. Esta última esfera se subdivide a su vez en tres campos: el de los bienes de subsistencia (productos agrícolas, herramientas pequeñas, etc.); la de los bienes de prestigio y de gran valor (bastones de metal, tejidos, medicinas, etc.); y la de los derechos sobre las personas (especialmente niños y mujeres), vinculado a las relaciones de parentesco, que ocupa el rango más alto. Estos campos están separados entre sí por compartimentos relativamente estancos. Los intercambios al interior de un campo dado, que Bohannan denomina como "transferencias", son fáciles y considerados normales. Al contrario, los intercambios entre campos, calificados por el autor como "conversiones", son mucho más difíciles de realizar. Los bastones de metal permitían el vínculo. Los tiv consideran recomendable intercambiar bienes de un campo inferior por los de un campo superior, convirtiéndose en "individuos en ascenso", y no en sentido inverso más que bajo una necesidad extrema. Tales esferas y campos de intercambio existirían en todas las sociedades, incluidas las sociedades (pos) industriales contemporáneas.

En una reconocida clasificación, Polanyi señala que han existido (y continúan presentes) tres modelos o formas de integración social: reciprocidad, redistribución e intercambio de mercado. La reciprocidad denota movimientos entre agrupamientos simétricos. Es la base de la organización de grupos como la familia, la vecindad ${ }^{6} \mathrm{o}$ las tribus. También de las asociaciones voluntarias o semivoluntarias de carácter militar, vocacional o religioso. La redistribución designa los movimientos de apropiación hacia un centro social (cima, líder, élite) y luego hacia el exterior o periferia (base social). Los productos se suelen mover a través de una jerarquía de funcionarios para ser almacenados, acumulados, en el centro. El flujo de bienes y/o servicios

${ }^{6}$ Sobre investigaciones en contextos urbanos de América Latina, y la importancia de la reciprocidad en la vida cotidiana, ver L. Adler-Lomnitz (1975 y 1994). Acerca de las instituciones de reciprocidad entre los pueblos indígenas de México, ver Warman (2003). 
invierten su sentido con el tiempo, surgen desde la cima y regresan a las bases sociales. El intercambio de mercado, por su parte, hace referencia a movimientos que tienen lugar entre manos en el sistema capitalista, y para servir de forma de integración requiere un sistema de formación de precios por el mercado. Ahora bien, Polanyi destacó que estas tres formas de integración no representan etapas de desarrollo (1976: 162), sino que suelen presentarse unas junto a otras en distintos niveles y sectores de la economía, siendo una dominante y las otras subordinadas.

\section{EL ENFOQUE DE LA EXCLUSIÓN SOCIAL}

El enfoque de exclusión social se ha desarrollado en las últimas tres décadas como un modelo alternativo de política social, entendiendo a la pobreza como un fenómeno global, centrándose en los procesos, los sujetos y la multidimensionalidad de las desventajas. Proporciona un marco para el análisis de las relaciones entre el sustento, el bienestar y los derechos ciudadanos. Inicialmente el concepto de exclusión social surgió en Europa (en Francia, Italia y los países nórdicos) en la década de los setenta para hacer referencia tanto a los problemas sociales de los inmigrantes como de los discapacitados, enfermos crónicos, jóvenes desempleados, etc., al interior de su propia sociedad: la gente que se encontraba "fuera" de la sociedad, "extramuros", los no ciudadanos (Tezanos, 1999) ${ }^{7}$. Sin embargo, en sus inicios esta interpretación pecó de dualista: los individuos estaban integrados o excluidos (Mongin, 2005), simplificando la realidad social. Castel ha presentado un esquema más complejo, en el que la sociedad no se encuentra fracturada en dos grandes grupos. Propuso este autor (1997) un esquema circular de tres áreas, denominando al núcleo como integración, a la zona que lo circunda como vulnerabilidad social y a la zona periférica como exclusión. Así destacó la precariedad creciente de los distintos estratos de la sociedad. En sus palabras:

Hay una zona de integración: se trata en general de personas que tienen un trabajo regular y soportes de sociabilidad bastante firmes. Hay una zona de vulnerabilidad: por ejemplo el trabajo precario, situaciones relacionales inestables. Y hay una tercera zona, la zona de exclusión, en la que caen algunos de los vulnerables e incluso de los integrados (1997: $58)$.

\footnotetext{
${ }^{7}$ El uso original del concepto de exclusión se suele atribuir al francés René Lenoir en su obra Les exclus: un francaise sur dix (1974), París, Ed. du Seuil.
} 
Asimismo, Mongin (2005: 250-252) releva el modelo de Donzelot (2004) acerca de las sociedades/ciudades postindustriales: la "ciudad de tres velocidades", una ciudad que se caracteriza por tres distintos sectores y circuitos que se mantienen a distancia: los excluidos o "inmovilizados", los sectores medios o "agotados" (por su gran movilidad espacial) y la élite o los "ubicuos". De modo que la exclusión es un proceso dinámico asociado a la estructura económica y urbana, que puede ser permanente o intermitente, pasando de una situación de vulnerabilidad a otra de dependencia, aislamiento e inmovilidad (Tezanos, 2002; Subirats, 2004 y 2005; Saraví, 2007). Como lo opuesto a la exclusión se señala la integración social, esto es, la exclusión es el resultado de un defecto de inserción y de integración. La "inserción" significa hacerse un lugar entre los otros, al lado, cerca de los otros, sin embargo es una situación que se caracteriza por la vulnerabilidad. La integración social aparece entonces como un largo proceso que se ha de recorrer, para lo que habrán de superarse diferentes etapas que dependerán de los distintos puntos de partida de cada individuo o grupo.

\section{SISTEMAS DE INTEGRACIÓN MIXTECA A LA CIUDAD DE MÉXICO}

Enumero aquí sintéticamente los principales resultados de la investigación que realicé entre los años 2006 y 2009, y finalizó algunos de los puntos con una interrogante que me parece oportuno plantearse en futuros estudios.

\section{Desventajas y ventajas en la entrada a la ciudad}

Los mixtecos rurales han sido, colectiva e individualmente, empujados a abandonar su tradicional hábitat, pues éste ya no les genera los recursos mínimos necesarios como para continuar su existencia en las localidades donde nacieron. Se enfrentan entonces al desafío de entrar en la ciudad, de insertarse en la sociedad urbana, buscando acceder así a una mejor vida. En este proceso de cambio de nicho ecológico, traen ad portas al menos dos desventajas y una ventaja. Primero, su nivel educativo formal suele ser muy bajo: más de la mitad de los sujetos entrevistados no supera la educación primaria (o incluso no asistió a la escuela). Segundo, suelen señalar los interlocutores que en la Ciudad de México su identidad de mixtecos, como también de oaxaqueños, son infravaloradas (no se les llama mixtecos sino indios, no se les denomina oaxaqueños, sino oaxacos: ambas categorías provistas de prejuicios negativos). 
Junto a estas desventajas, se reconoce en sus discursos y prácticas un activo que muchas veces no es considerado/reconocido en los estudios antropológicos: cada sujeto pertenece a un colectivo, a un entramado social paralelo y entrelazado a su condición de ciudadano mexicano, son miembros del pueblo mixteco (identidad que se fortalece en la gran ciudad, lejos de su contexto de origen) y, por tanto, en la medida en que cada uno aporte sus contribuciones para los trabajos comunitarios, cuentan con un capital social y cultural que suele resultar muy útil ante el desafío de continuar sus vidas en otro espacio geográfico y social, en otro estado y en un contexto que suele caracterizarse por un estilo de vida diferente al campesino y rural: el mundo urbano y megapolitano.

Hay también una segunda ventaja con la que han dispuesto los habitantes de esta colonia hasta hoy día. Es un recurso adquirido, que ha sido logrado a través de la "unión" entre todos los vecinos, más allá de sus particularidades: es la Unión de Colonos San Miguel Teotongo (UCSMT) ${ }^{8}$. En esta institución civil mediadora los colonos han encontrado un gobierno local de facto al cual acudir y demandar (junto con participar y solidarizar en sus propósitos), un lugar en el cual se les brinda apoyo y gestión, otorgándoles un piso/base mínimo de seguridad.

\section{¿Lazos sociales laxos?}

Ahora bien, los estudios urbanos suelen señalar que los lazos sociales en las ciudades se diluyen y que la mayoría de las interacciones son individuales, insignificantes y anónimas. El sujeto urbano, que vive en ámbitos sociales modernos y complejos, constituiría parte de una muchedumbre solitaria; el contexto citadino, más aun el megapolitano, actuaría como un disolvente de las prácticas tradicionales y de las identidades étnicas. Esto lo ha advertido la sociología urbana desde sus inicios (Wirth, 1938). Por su parte, la antropología socio-cultural ha señalado (Redfield, 1941; Gellner, 1983) que cuando los sujetos pertenecientes a grupos étnicos migran desde el campo a la ciudad, o desde el pueblo a la capital nacional, tienden a desorganizarse y atomizarse -recordándonos el concepto de anomia (Durkheim, 1893)-: cada uno busca encontrar su propio acomodo en la "selva de cemento".

\footnotetext{
${ }^{8}$ Esta asociación civil se creó en 1975 como parte del movimiento urbano popular (MUP), distante del Partido Revolucionario Institucional (PRI) y de toda instancia partidista. La UCSMT se dedicó inicialmente a investigar la situación jurisdiccional y de propiedad de los terrenos de la colonia y empezó a celebrar asambleas abiertas en las cuales discutir los problemas existentes.
} 
Parte de la reciente antropología ha afirmado también que la presentación del sujeto indígena como tal ante la sociedad urbana y nacional suele ser sólo una estrategia, una acción (elección) racional, una apariencia que se actúa con el propósito de ser aceptado y de este modo poder insertarse en las nuevas redes de la modernidad citadina.

Los hechos observados a lo largo de este estudio, la información y los testimonios recopilados permiten complejizar y trascender lo afirmado por estos y otros modelos teóricos. Más que optar por uno u otro esquema, los datos nos llaman a despurificar tales enfoques, intentando dar cuenta de la realidad empírica observada. Esta idea de lo que podríamos denominar como "lazos urbanos laxos" es claramente desmentida en el caso de los vínculos entre los inmigrantes oaxaqueños, también -aunque en menor medida- en la primera generación nacida en la ciudad, y ha de estudiarse, en futuras investigaciones, para el caso de la segunda generación nativa urbana (esto es, la que suele llamarse "tercera generación"), que parece tender hacia un estilo de vida más cercano a lo advertido por los sociólogos urbanos.

Pese a vivir en el contexto predominante de un sistema capitalista de mercado, que sólo concibe a los seres humanos como individuos/ciudadanos, los mixtecos muestran, a través de su vida cotidiana, que también pertenecen a determinados pueblos/grupos étnicos, a concretos "mundos de la vida" (Habermas, 1987). De este modo, nos recuerdan la condición social de las personas, por lo que junto con ser parte de una sociedad común, la mexicana (el ámbito mayor de coexistencia social), también son miembros de dominios culturales específicos (Martínez y De la Peña, 2004), los que, pese a su diversidad, comparten una matriz cultural mesoamericana que se caracteriza por sus propias instituciones. En este sentido, cabe destacar la continuidad de los planteamientos de Adler-Lomnitz (1975) respecto a la relevancia de las redes de intercambio recíproco de bienes y servicios en la sobrevivencia de los sectores económicamente menos favorecidos de la población de Ciudad de México. Estas redes representan un sistema de seguro cooperativo informal que suplen mediante la ayuda mutua los efectos de la inseguridad laboral y la carencia de seguros sociales en los empleos flexibles, de manera que la estructura social de las colonias y barriadas se asemejan a un conjunto de redes.

\section{Economía moral: la guetza}

Dicho esto, no se trata sólo de afirmar que los mixtecos cuentan con una modalidad de protección social que les brinda su red de parentesco, dada 
la confianza existente entre sus miembros. Debemos hoy en día especificar cuáles son los principios y prácticas que posibilitan tales conexiones y cómo éstas se encuentran entretejidas al interior de redes más amplias y posiblemente más ajenas. Un principio básico compartido de este capital cultural mesoamericano/mixteca es la guetza, esto es, la norma por medio de la cual se apoyan unos a otros más allá de si viven en asentamientos concentrados o dispersos en la colonia y ciudad. Este principio (de acuerdo a lo planteado por los diversos sujetos) es tanto un derecho como un deber, o, más bien, es un compromiso cuanto que un valor, deviniendo una norma que se continúa practicando al interior de la urbe por medio de la práctica del tequio ${ }^{9}$ (entre otras acciones) y en la interrelación campo-ciudad, como también con quienes residen en el extranjero. Encontramos aquí lo que Thompson (1971) y Scott (1990) denominaron como "economía moral", la que proviene de una ética de la subsistencia que intermedia entre los individuos y un grupo social determinado en un ambiente de alta vulnerabilidad.

Las expresiones de dos de los entrevistados de: "te apoyo para que mañana tú me apoyes..." (Taurino) y "dando y dando, pajarito volando..." (Gregoria), son explícitas acerca de la conveniencia colectiva de estas prácticas $^{10}$-recordándonos al respecto los análisis sobre el don de Mauss (1925) y Lévi-Strauss (1969)-, transgrediéndose así la frontera de la dicotomía entre tradición y modernidad que se suele usar aún hoy en los estudios socioculturales, como también la oposición de la antropología entre la corriente económica formal y la substantiva ${ }^{11}$.

Ambas explicaciones del comportamiento económico son necesariamente complementarias para dar cuenta de las sociedades indígenas contemporáneas. Los hechos muestran, especialmente en los inmigrantes (en menor grado en los nacidos en la ciudad), que la explicación formal depende de la substantiva (o bien debe substantivizarse), pues un requisito previo para cualquier comportamiento de cálculo es la pertenencia a una sociedad/ cultura con que se identifican los individuos. Se trata, así, de "elecciones sig-

\footnotetext{
${ }^{9}$ El tequio es el trabajo colectivo que cada miembro de una comunidad mixteca debe aportar desde que cumple los 18 años. Es una de las manifestaciones del principio de la guetza.

${ }^{10}$ No se trata propiamente de "economía simbólica", en el sentido de Bourdieu (1994), pues no se basa en la represión o la censura del interés económico (lo que este autor denomina como el "desconocimiento compartido").

${ }^{11}$ En las décadas de los sesenta y setenta hubo en la antropología económica una polémica entre el enfoque formal y el substantivo. El primero releva el cálculo cuantitativo implicado en la toma de decisiones económicas y el segundo subordina la actividad económica a normas de valor de índole cualitativa.
} 
nificativas" (Kymlicka, 1996). La guetza, por ende, es una "regla práctica" (Ingold, 1996) o bien una "opción colectiva racional" (Sen, 2002) y las instituciones/acciones cotidianas a las que conduce permiten obtener la mejor posición posible, satisfaciendo a la vez necesidades biológicas y sociales.

Diría -recordando a Giddens (1990) y Bourdieu (1994), respectivamente- que estas interacciones sociales son producto de una "conciencia" o "razón práctica" que anula la oposición clásica entre interés y altruismo, o remontándonos a Weber (1922): ambos aspectos de la racionalidad humana, el cuantitativo (formal) y el cualitativo (substantivo) se presentan al unísono. Es más, este hecho nos confronta a una paradoja económica. De acuerdo a la economía formal, es en el sistema de mercado, cuando los seres humanos se dejan llevar por su egoísmo, que se obtienen beneficios para todos. Al trabajar y competir -se señala- se consigue el propio provecho y también el de los otros.

Aquí, en cambio, lo que encontramos es que, a través de la realización cotidiana del principio de la guetza, del dar hoy y recibir mañana, los mixtecos logran muchas veces satisfacer sus necesidades individuales y colectivas. Nadie está forzado a participar en tal o cual asociación, en tal o cual red de vecinos (consanguíneos o afines), sin embargo todos se sienten obligados a hacerlo. Es que la autoexclusión de tales círculos sociales implicaría una actitud hostil, y con ella la pérdida de estimación y de prestigio, provocando aislamiento, y tal aislamiento conduciría paulatinamente a vivir en condiciones de privación, en fin, de pobreza. Parafraseando a Lévi-Strauss (1969), diría que el tabú de la pobreza (material y social) es el origen del intercambio de bienes y servicios. Queda pues esta paradoja como una segunda interrogante para futuras investigaciones: $¿$ no es que los valores empiezan donde termina la eficiencia y que la eficiencia (el comportamiento óptimo) es un asunto del sistema de mercado?

\section{Enclaves y asociaciones étnicas}

Los mixtecos se encuentran reunidos territorialmente en una u otra sección (barrio) de la colonia. Esta concentración espacial tiende a generar el hábito del vínculo entre unos hogares y varios otros, construyéndose un complejo círculo de intercambios que no solamente conecta a distintas familias en el espacio sino que también liga a diversos momentos en el tiempo (por 
medio de la tanda ${ }^{12}$, de la venta de "pan oaxaqueño", etc.), reduciendo las incertidumbres de los gastos del "mañana". No corresponde aquí referirse a estas concentraciones étnicas como a guettos urbanos, pues son espacios que disponen de un buen acceso a los bienes de consumo colectivo (equipamiento y transporte) y que no se caracterizan por una estable homogeneidad económica (como tampoco por la degradación social). Nos enfrentamos entonces a enclaves étnicos, esto es, a aglomeraciones residenciales y laborales (Portes, en Valenzuela, 2007) de mixtecos con una permanente heterogeneidad intrasocial así como de continuos intercambios con otros espacios de la colonia y ciudad.

Por su parte, la dispersión/fragmentación típica de las megalópolis contemporáneas se subsana parcialmente a través de la organización de los inmigrantes y sus hijos en asociaciones étnicas cuyo eje es la raíz común de sus respectivos pueblos/lugares de origen -la "comunidad moral" (Cohen, en Martínez y De la Peña, 2004). Ambas "comunidades", la barrial (de vecinos) y la asociacional (de paisanos), son proclives a generar rutinas que disminuyen el/los riesgo/s y otorgan "seguridad ontológica" a las personas (Giddens, 1990).

Entonces, se observa una cierta similitud entre el "viejo" orden étnico (rural) y el nuevo orden posindustrial (urbano) que construyen estratégicamente los inmigrantes y sus hijos en la colonia: estratificación social (local y permeable), concentración étnica, cultura diversificada y discontinua (de acuerdo a las identidades comunitarias, mas con un sustrato común), transmitida principalmente por los grupos locales y el trabajo familiar. Sin embargo, en la ciudad aumenta la conciencia de la propia cultura, de la propia "distintividad" colectiva, siendo cotidianos los encuentros entre miembros de un mismo grupo étnico ya sea por motivos políticos (no partidistas), festivos o deportivos, especialmente los días domingo. Así, los mixtecos viven hoy (sobre todo los inmigrantes) entre dos escalas territoriales y morales: una con base rural, segmentada, basada en la creencia (y prácticas festivas) en los santos locales; y otra con base urbana, tan segmentada como

\footnotetext{
${ }^{12}$ La tanda es una institución de ahorro y crédito informal característica de los sectores de clase media y baja en México (Vélez, 1983). En la colonia participan regularmente diez miembros (familiares, vecinos y/o compañeros de trabajo) más quien la organiza, que suele ser una mujer. Cada miembro se compromete a entregar una cuota semanal y los once números se entregan de acuerdo a las solicitudes de cada participante, llegándose a un consenso. Así, por ej., si la tanda se organiza a principios de enero y alguien pide el número ocho, recibe el fondo común en el mes de agosto. Esta es una práctica de "economía moral" que permite planificar gastos que se tienen previstos a lo largo del año en curso.
} 
articulada (una "anarquía ordenada") y cada día más secularizada ${ }^{13}$. Se produce así un nuevo orden étnico, que se desarrolla de abajo hacia arriba, por fusión, inter-comunicativamente. Este nuevo orden se genera como respuesta a los nuevos riesgos/vulnerabilidades a los que se ven enfrentados sus miembros al tener que reubicarse ya sea en ciudades mexicanas o estadounidenses, entre distintos estados y estados-naciones. El peligro de la mayor exposición al exterior (nacional y global) tiende a cohesionar, la hostilidad del mercado urbano contemporáneo ( $y$ de la sociedad dominante) re-caracteriza holísticamente al grupo étnico.

\section{La generación nacida en la ciudad y el capital humano}

Ahora bien, pese a esta continuidad cultural multisituada basada en la "ciudadanía étnica" (De la Peña, 2005) e identidad residencial de cada "rumbo" o poblado oaxaqueño, el principio cooperativo de la guetza se ve debilitado, erosionado por el ethos circundante en la Ciudad de México y el mundo urbano occidental (y especialmente estadounidense en este caso), basado en la competencia y la ganancia individual. De este modo, al pasar de la generación inmigrante a la de sus hijos (los nacidos en la ciudad) se revela el paso de redes internas y compactas a contactos externos y fluidos, adquiriendo más importancia en la vida cotidiana las trayectorias y vínculos individuales, egocéntricos, que las mallas densas -a veces "sobre-comuni-

\footnotetext{
${ }^{13}$ Bartolomé (1997) releva el primer nivel identitario por sobre el último, sin embargo -dada la actual situación urbana y transnacional- más bien habría que empezar a relevar el segundo (lo étnico o etnolingüístico) por sobre el primero (lo comunitario o residencial), aunque en el espacio comunitario el sentimiento de pertenencia sea más intenso. Quizá haya que recordar a Barth (1976), en quien se basa Bartolomé, que al caracterizar a un grupo étnico como un tipo de organización social (basado en la interacción), no se refiere en su texto necesariamente a una interacción cotidiana y presencial, típica de las comunidades rurales, sino a una cohesión interna más allá de las distancias físicas existentes entre sus miembros, esto es, a una "comunidad moral" o bien a una "ciudadanía moral". Las fronteras étnicas, más que territoriales, son normativas. Esta articulación étnica no se basa (como condición) en los encuentros cara a cara, sino en el mantener la comunicación (más o menos fluida) y cumplir con los compromisos entre quienes se adscriben a uno u otro grupo étnico. Los pueblos (grupos étnicos) -tal como las naciones- son comunidades imaginadas (Anderson, 1983), pues suelen no conocerse entre sí todos sus miembros. Finalmente, es de destacar que la distinción efectuada por este autor entre grupo étnico y grupo etnolingüístico, de acuerdo a las diferencias dialectales entre los hablantes de una lengua, no resulta relevante en el mundo urbano, pues lo distintivo es el ser, por ejemplo, mixteco o chocholteco u otomí, etc., y no las distinciones internas (culturales) existentes en cada pueblo. Esto es, el criterio que prima en la pertenencia étnica no es el territorial como tampoco el de las diferencias objetivas intraculturales, sino que la conciencia y el cosentimiento (la autoadscripción y heteroadscripción) de pertenecer a un mismo pueblo.
} 
cadas", como señalara Goffman (cit. por Martínez, 2007)- basadas en el parentesco, la contigüidad territorial y el paisanazgo. Podríamos decir que cambian de nudo en la red social, adquiriendo ahora también un lugar (o un mejor lugar) en las (sub)redes mercantiles y estatales.

Dicho de otro modo, en la generación nacida en la megalópolis (después de los años setenta, e hijos, por tanto, de la época que se suele denominar como modernidad tardía/alta o posmodernidad) se suma, al capital cultural y social recibido, el capital humano generado al participar en las instituciones urbano/nacionales/transnacionales, dada la relevancia que tienen los estudios secundarios, técnicos o universitarios, así como las experiencias laborales en las distintas urbes mexicanas y de los Estados Unidos (especialmente California), en la ampliación de las comunicaciones (e informaciones) y en la apertura de nuevas posibilidades de trabajo remunerado. De modo que el (nuevo) conocimiento técnico y social posibilita la obtención de mayor manejo de dinero y crédito $-\mathrm{y}$ por tanto un superior poder de compra y uso/acumulación/ostentación de cosas, lo que genera en unos la distribución e inversión en tanto que en otros el derroche individual y/o colectivo de la riqueza momentánea- propendiendo a un desarraigo que sin embargo suele devenir en un rearraigo; esto es, hay una continuidad en el sentimiento de pertenencia a la familia/poblado/etnia, pero desde un yo ampliado. La obtención de mayor riqueza de parte de algunos no se evalúa en la colonia como una falta si es que tales personas o familias siguen cumpliendo con sus obligaciones comunitarias. Por tanto, la "economía moral" (Thompson, 1971 y Scott, 1990) no se restringe al principio de igualdad, sino que se abre en el escenario urbano a la riqueza de quienes la consigan mediante el trabajo.

Esto no significa que esta parcial cosmopolitización de los inmigrantes y sus hijos (debido al aumento de su movilidad) así como la estratificación económica que se genera en su interior, no implique un riesgo (así como sentimientos de envidia en algunos) para la cohesión social étnico/ comunitaria, pues así como la escasez entre semejantes tiende a impulsar la reciprocidad, la fragmentación y diferenciación tienden a aumentar el sentimiento de distancia social y por tanto las actitudes egoístas -lo que han advertido Adler-Lomnitz (1975) y Sahlins (1976a) en otros contextos sociohistóricos-; es el control de estas actitudes individualistas lo que se exige, y no ya el permanecer al interior de ciertos límites de prosperidad.

Los mixtecos transitan poco a poco desde personas a individuos ( $\mathrm{Da}$ Matta, 1997), viviéndose una tensa complementariedad entre las tramas corporativas del entorno familiar y las cada vez mayores interacciones con 
extraños/compañeros de trabajo/amigos que permiten la extensión de las oportunidades laborales/vitales y con ello los deseos de mayor ganancia y prestigio, mas desde estas conexiones ampliadas se suele ayudar-desde una nueva situación/estatus individual-a la reproducción material y social "del rumbo" oaxaqueño. De manera que más que de individualización, en el sentido que Dumont (1987) da a este término (el individuo todopoderoso opuesto a los colectivos holísticos), lo que encontramos en los inmigrantes y sus hijos residentes en la colonia San Miguel Teotongo es un paulatino proceso de individuación (Jung, 1981), esto es, unas circunstancias por las que el sujeto deviene un ser autopercibido como disponiendo de una mayor autonomía (con más capacidades/habilidades/competencias: con mayor capital humano) como también de ciudadanización. La pregunta que aquí surge, entonces, se refiere a la "tercera generación" de mixtecos en la ciudad: ¿Encontraremos en ellos sujetos individualizados (en la acepción de Dumont), esto es, impersonalizados, típicos de la cultura de masas de las sociedades tardomodernas?

\section{El centro político de la colonia y las redes jerárquicas}

Siguiendo el modelo socioespacial propuesto por Lefebvre (1968 y 1972) y Delgado (1999) (polis/espacio colectivo/urbs) ${ }^{14}$, el "centro político" o polis local (la UCSMT) -que fuera creado en 1975 y que hasta fines de esa década se organiza de manera jerárquica, dirigida por caciques, democratizándose a partir de los años ochenta- pierde autonomía ante la entrada "del partido" (Partido de la Revolución Democrática, PRD, triunfante en el Distrito Federal desde 1997), pues muchas de las decisiones a partir de ese momento se realizan en otro lugar/ámbito: esto es, ya no se toman en el espacio de la sociedad civil, sino que desde diversas instituciones estatales que "se acercan" (a través de los intermediarios: diputados PRD surgidos en la UCSMT) a la periférica colonia. En el mismo recinto donde se generó la composición de lo colectivo -a partir de la multitud de inmigrantes- se decidió ser representados, introduciéndose el fantasma de la división y la duda en la fidelidad de la traducción de los intereses compartidos. Sin embargo, esta pérdida gradual de potestad de la asociación civil se vio recompensada por los beneficios logrados a través de las nuevas redes jerárquicas que conectan

\footnotetext{
${ }^{14}$ En este modelo, polis corresponde al espacio político; el "espacio colectivo" representa el hábitat residencial; y urbs denota el espacio público.
} 
a los colonos con los organismos gubernamentales (en sus distintos niveles): el Estado (estatal y federal) y sus dones "llegan" a la colonia.

Estos procesos implican un paso desde los intercambios típicamente recíprocos, fundados en redes horizontales (igualitarias) -los que se mantienen en los distintos "espacios colectivos" o hábitat residenciales, y especialmente en los enclaves étnicos-, hacia una forma de integración social en el espacio público mayoritariamente redistributiva, fundada en redes verticales (jerárquicas), en el contexto del predominio nacional y mundial de las interacciones de mercado (Polanyi, 1944; Harvey, 1973). De modo que la hegemonía de la economía mercantil-capitalista -o de la "economía urbana", como escribiera Weber (1904) - y su tendencia a la exclusión social ha sido apaciguado/“dulcificado" en San Miguel Teotongo durante ya más de tres décadas tanto por los espacios/prácticas (favores) producidos por los vecinos en cada hábitat residencial (la "economía privada") como por la labor conjunta de los colonos en la UCSMT y a través de los vínculos/ lealtades de ésta con el PRD y los servicios obtenidos por medio de las instituciones estatales (la "economía política"): Fonhapo e Invi (vivienda); Conasupo y Liconsa (productos básicos); pensión a los adultos mayores y protección médica a quienes no disponen de seguro.

Ahora bien, esta pérdida de protagonismo y de representatividad de la UCSMT acontecida a lo largo de la década de 1990 fue acompañada paralelamente por un repliegue de las personas al ámbito de la vida cotidiana, de la reproducción familiar, en pro de asegurar las condiciones de existencia. El mundo de la vida (la acción comunicativa) fue opacado por el sistema (la acción instrumental) (Habermas, 1987), la economía mercantil se impuso sobre la polis, reduciéndose la dinámica de la cotidianidad al ámbito de lo doméstico y del barrio, pero ya no de la colonia como un todo. Más que nunca en la historia de la colonia se impuso, pues, el criterio pragmático del "mínimo costo/máximo beneficio". De modo que, a lo largo de estas ya casi cuatro décadas, han existido en la colonia cuatro tipos diferentes de dinámica política: (1) el movimiento vecinal por oposición al partido/gobierno (PRI) y a toda instancia partidaria, (2) las políticas públicas (federales y estatales) clientelísticas, (3) el cobijo de la organización vecinal bajo el PRD $y$, (4) el funcionamiento paralelo, desde los inicios de la colonia, de las distintas asociaciones étnicas vinculadas a sus poblados de origen.

Acceso a la estructura laboral: los intercambios de mercado

Se identifican hoy entre los mixtecos de la colonia cuatro factores que in- 
fluyen (aunque no de manera determinante) en el acceso diferencial a la estructura de trabajo y por ende en la inserción/integración social de los vecinos: 1) Grado de escolaridad: vendedores ambulantes, cargadores, tianguistas $^{15}$, albañiles, trabajadoras de la maquila en domicilios/empresas de la colonia y empleadas domésticas (fuera de la colonia) son quienes cuentan con un nivel más bajo de escolaridad, no superando sexto año de primaria (de educación básica), y a su vez quienes reciben los ingresos más bajos. Las dos últimas ocupaciones (en la maquila y como empleadas domésticas, desempeñadas por mujeres) se distinguen por contar con un salario estable (aunque sin ningún tipo de seguridad laboral). Los ingresos más altos en cambio los perciben aquellos que desempeñan labores relacionadas con el comercio (siendo propietarios de locales), los obreros especializados y los técnicos/profesionales. Ahora bien, sólo en estos últimos es clara la diferencia en el grado de educación formal; 2) Tiempo de estancia en la ciudad: quienes han vivido durante más tiempo en la Ciudad de México suelen contar con una mayor especialización en un determinado oficio, así como redes sociales más extensas, lo que repercute positivamente en su estabilidad laboral y permite cambiarse de lugar de trabajo (a otro similar al anterior) cuando se es despedido o se siente individualmente la necesidad de hacerlo. De manera que un largo período de residencia en la urbe tiende a evitar prolongados espacios de tiempo sin empleo; 3) Pertenencia política: participar en la UCSMT y/o en el PRD facilita el acceso a empleos y a contar con protección; 4) Origen de clase rural: quienes ya desempeñaban un oficio en sus localidades rurales de origen suelen desempeñar idénticas ocupaciones en la ciudad, por lo cual este "punto de partida" condiciona el grado de integración socio-laboral y las posibilidades de movilidad social ascendente en la urbe.

Con respecto a este último punto, se destaca en la colonia que los mercados laborales continúan socialmente segmentados y que esta fragmentación (especialmente en quienes inmigraron) se basa a menudo en diferentes especialidades. En los testimonios se revela que la "producción para el uso" o "para el consumo" de los campesinos (aprovisionamiento) -la élite económica rural oaxaqueña suele comercializar ganado y otros bienes-, en la colonia periférica deviene "producción para el cambio" o "para el intercambio [de mercado]" (el lucro característico de las actividades comerciales). Ahora bien, la capa social de comerciantes y artesanos, que en el

${ }^{15}$ El tianguis corresponde a la feria en Chile. Por lo tanto, los tianguistas son los dueños y trabajadores de locales en las ferias de la colonia y sus alrededores. 
mundo rural de la mixteca suele representar el estrato intermedio (entre la base campesina dedicada a la producción de autosubsistencia y la élite política-clerical) se extiende hacia arriba y hacia abajo de la escala social, no habiendo ya grandes propietarios con suficiente poder como para ejercer la coacción sobre los otros (los caciques se vinculan más bien a ámbitos político-partidistas).

La estratificación social y los "grandes hombres"

La destreza en los oficios es transmitida a los más jóvenes por sus parientes durante la misma práctica del trabajo, en la forma de maestro/aprendiz. Sobre esta base tradicional, se introduce con más énfasis en la Ciudad de México la monetarización y el valor de la ganancia en las interacciones cotidianas, por lo cual los empleadores mantienen, aunque generalmente sin seguros sociales, económicamente a sus empleados -familiares y vecinos-, generándose lazos de patronazgo. Es en la medida que estos pequeños empresarios crecen comercialmente que devienen grandes hombres o big men de acuerdo a la terminología antropológica (Sahlins, 1976a,b; Godelier, 2000), quienes logran un pequeño poder a partir de su capacidad para acumular riqueza e invertirla en más empleados y/o locales y/o tecnología. Este comerciante se transforma así en un jefe cuyo nombre es reconocido en cierto sector de la colonia, pero que no tiene más influencia directa que sobre su mano de obra. Esta parcial capacidad de influir sobre los demás no se basa entonces en la coacción sino en el acuerdo entre los trabajadores y el jefe en que éste desempeña (al menos temporalmente) un papel fundamental en la reproducción de sus familiares y vecinos -es la denominada "dominación simbólica", producto del capital simbólico del jefe (Bourdieu, 1994)-.

Estas representaciones compartidas se sustentan en los intercambios redistributivos: empleo y estabilidad económica a cambio de lealtad y prosperidad. Se desarrollan así relaciones asimétricas de patronazgo diádico que suelen proyectarse, en los casos en que residen empleadores y empleados en la misma vivienda (aunque en distintos pisos: en el de abajo los empleadores, en los de arriba los empleados), a la vida de la casa, obstaculizando la formación de una privacidad y tiempo de ocio en los empleados. De modo que las relaciones intra-familiares e intra-étnicas se mercantilizan, facilitando el surgimiento de tensiones en las relaciones personales y familiares. 
Como vemos, entre los mixtecos de San Miguel Teotongo se encuentran actualmente al menos dos niveles económicos, dos "velocidades" (Donzelot, en Mongin, 2005) de vida urbana, no siendo pertinente la categoría de "inmovilizados" (excluidos) para gran parte de su población, aunque observándose una particular vulnerabilidad en la tercera edad, la que no siempre es apoyada por sus familiares. Ambos estratos son permeables, siendo la formación en un oficio y la participación en sus respectivas redes un aspecto prioritario para poder ascender socioeconómicamente. Estas dos capas sociales se retroalimentan día a día a través de la llegada de nuevos inmigrantes a la colonia, así como con los jóvenes (nacidos en la ciudad) que se incorporan a la vida laboral, constituyendo el nivel inferior. Algunos de ellos logran alcanzar una vida económicamente independiente (el nivel superior) al adquirir propiedades y crear sus propios negocios.

En ambos estratos se pueden distinguir (como plantea Roberts, 1996) diferentes estrategias familiares: en el primero (nivel inferior) se encuentran orientadas fundamentalmente a la sobrevivencia, caracterizándose por un horizonte temporal de un año, plazo durante el cual se logran los beneficios para satisfacer las necesidades (materiales y simbólicas) más inmediatas. El segundo estrato (nivel superior), en cambio, se caracteriza más bien por estrategias de movilidad social ascendente, las que involucran mecanismos de distribución, tales como la educación de los niños, la compra de un terreno o local, decisiones que verán resultados a largo plazo.

Los mixtecos de esta colonia se caracterizan laboralmente, entonces, por agrupaciones familiares que desarrollan una actividad en la que los asalariados (típicos de la época del Estado de bienestar) son minoritarios en las prestaciones laborales, por lo que las ganancias mensuales suelen variar de mes a mes, salvo en los empleados. Se trata de unidades de convivencia, trabajo y consumo en las que el precio de las mercancías es el regulador de la producción y del intercambio. No son unidades económicas precapitalistas ni anticapitalistas, sino paracapitalistas: pequeños empresarios y trabajadores por cuenta propia que gozan de cierta autonomía pero en cuya (muchas veces) informalidad se hallan al mismo tiempo los riesgos de mantener lo ya logrado; o bien empleados o jóvenes técnicos/profesionales que buscan estabilidad laboral (no sólo empleos flexibles) a través de un trabajo más individualizado, proyectándose a una futura integración social. 


\section{AGRADECIMIENTOS}

Quiero agradecer a todos/as y cada uno de los vecinos mixtecos que me brindaron su recepción y amistad en la colonia, así como el rico diálogo generado a partir de las interrogantes que surgieron durante el trabajo de campo. Este texto forma parte de los resultados de mi investigación de tesis de Doctorado realizada en el Instituto de Investigaciones Antropológicas (IIA), Universidad Nacional Autónoma de México (UNAM). Agradezco asimismo a la Universidad de Concepción y al Ministerio de Planificación (MIDEPLAN), instituciones que financiaron mis estudios de Doctorado (2006-2009).

\section{REFERENCIAS}

Adler-Lomnitz, Larissa (1975). Cómo sobreviven los marginados. México: Siglo XXI.

------ (1994). Redes sociales, cultura y poder. Ensayos de Antropología Latinoamericana. México: FLACSO \& M. A. Porrúa.

Arizpe, Lourdes (1975). Indígenas en la Ciudad de México. El caso de las 'Marías'. México: SEP-Setentas.

Barth, Fredrik (1976). Los grupos étnicos y sus fronteras. México: FCE.

Bartolomé, Miguel (1997). Gente de costumbre y gente de razón. Las identidades étnicas en México. México: Siglo XXI.

Bohannan, Paul (1962). Some principles of exchange and investment among the tiv. En E. Leclair \& H. Schneider (Eds.), Economic Anthropology. Reading in theory and analysis. New York: Holt, Rinehart and Winston, Inc.

Bourdieu, Pierre (1994). Razones prácticas. Sobre la teoría de la acción. Barcelona: Anagrama.

Butterworth, Douglas (1962). "A study of the urbanization process among Mixtec migrants from Tilantongo in México City", en América Indígena, Vol. 22, III.

------ (1971). “Migración rural-urbana en América Latina: el estado de nuestro conocimiento", en América Indígena, Vol. 31, III.

Castel, Robert (1997). La metamorfosis de la cuestión social. Buenos Aires: Paidós.

Comisión Nacional para el Desarrollo de los Pueblos Indígenas (CDI) (2002). Sistema de Indicadores sobre la población indígena de México. CDI-PNUD, en sitio web: http://www.cdi.gob.mx/index.php?id_seccion=660 \& http:// www.cdi.gob.mx/index.php?id_seccion $=90$

Da Matta, Roberto (1997). Carnavales, malandros y héroes. Hacia una sociología del dilema brasileño. México: FCE.

De la Peña, Guillermo (2005). Identidades étnicas, participación ciudadana e 
interculturalidad en el México de la transición democrática. En L. Reina, F. Lartigue, D. Dehouve y C. Gros (Coords.), Identidades en juego, Identidades en guerra. México: CIESAS, CONACULTA \& INAH.

Delgado, Manuel (1999). El animal público. Hacia una antropología de los espacios urbanos. Barcelona: Anagrama.

Dumont, Louis (1987). Ensayos sobre el individualismo. Madrid: Alianza.

Durkheim, Emile (1893). La división del trabajo social. Madrid: Akal.

Gellner, Ernest (1983). Naciones y nacionalismo. Madrid: Alianza.

Giddens, Anthony (1990). Consecuencias de la modernidad. Madrid: Alianza.

Godbout, Jacques (en colaboración con Alain Caillé) (1997). El espíritu del don. México: Siglo XXI.

Godelier, Maurice (1981). Instituciones económicas. Barcelona: Anagrama.

------ (1998). El enigma del don. Barcelona: Paidós.

------ (2000). Cuerpo, parentesco y poder. Perspectivas antropológicas y críticas.

Quito: Pontificia Universidad Católica del Ecuador.

Habermas, Jurgen (1987). Teoría de la acción comunicativa. México: Taurus.

Harvey, David (1973). Urbanismo y desigualdad social. México: Siglo XXI.

Hirabayashi, Lane (1984). "Formación de asociaciones de pueblos migrantes a México: mixtecos y zapotecos", en América Indígena, Vol. XLV, № 3, III.

Ingold, Tim (1996). "El forrajero óptimo y el hombre económico". En P. Descola y G. Pálsson (Coords.), Naturaleza y sociedad. Perspectivas antropológicas. México: Siglo XXI.

Jung, Carl (1981). Arquetipos e inconsciente colectivo. Barcelona: Paidós.

Kemper, Robert (1976). Campesinos en la ciudad. Gente de Tzintzuntzan. México: Sep-Setentas.

Kymlicka, Will (1996). Ciudadanía multicultural. Barcelona: Paidós.

Lefebvre, Henri (1968). El derecho a la ciudad. Barcelona: Península.

----- (1972). Espacio y política. El derecho a la ciudad, II. Barcelona: Península.

Lévi-Strauss, Claude (1969). Las estructuras elementales del parentesco. Buenos Aires: Paidós.

Lomnitz, Claudio (2005). "Sobre reciprocidad negativa". Revista de Antropología Social 14, Madrid: UCM.

Malinowski, Bronislaw (1922). Los argonautas del pacífico occidental. Barcelona: Península.

Martínez, Regina (2007). Vivir invisibles. La resignificación cultural entre los otomies urbanos de Guadalajara. México: CIESAS.

Martínez, Regina y De la Peña, Guillermo (2004). "Migrantes y comunidades morales: resignificación, etnicidad y redes sociales en Guadalajara”. En P. Yanes, V. Molina y O. González, Ciudad, pueblos indígenas y etnicidad. México: UCM y Dirección General de Equidad y Desarrollo Social.

Mauss, Marcel (1925). "Ensayo sobre el don”. En Sociología y antropología. Madrid: Tecnos.

Molina, Virginia y Hernández, Juan (2006). "Perfil sociodemográfico de la población indígena en la Zona Metropolitana de la Ciudad de México, 2000. 
Los retos para la política pública”. En P. Yanes, V. Molina y O. González (Coords.), El triple desafío. Derechos, instituciones y politicas para la ciudad pluricultural. México: Gobierno del Distrito Federal-Secretaría de Desarrollo Social \& UACM.

Mongin, Olivier (2005). La condición urbana. La ciudad a la hora de la mundialización. Buenos Aires: Paidós.

Oehmichen, Cristina (2005). Identidad, género y relaciones interétnicas. Mazahuas en la Ciudad de México. México: UNAM-IIA-PUEG.

Polanyi, Karl (1944). La gran transformación. Los orígenes políticos y económicos de nuestro tiempo. México: FCE.

----- (1976). El sistema económico como proceso institucionalizado. En M. Godelier (Comp.), Antropología y economía. Barcelona: Anagrama.

Pozas, Ricardo (1948). Juan Pérez Jolote. Biografía de un tzotzil. México: FCE.

Redfield, Robert (1941). Tepoztlan, a mexican village: a study of folk life. Chicago: University of Chicago Press.

Roberts, Bryan (1996). "Estrategias familiares, pobreza urbana y prácticas ciudadanas. Un análisis comparativo". Anuario de estudios urbanos, № 3, México: UAM-Azcapotzalco.

Sahlins, Marshall (1976a). "Economía tribal”. En M. Godelier (Comp.), Antropología y economía. Barcelona: Anagrama.

----- (1976b). Cultura y razón práctica. Barcelona: Gedisa.

Saraví, Gonzalo (2007). Nuevas realidades y nuevos enfoques: exclusión social en América Latina. En G. Saraví (Ed.), De la pobreza a la exclusión. Continuidades y rupturas de la cuestión social en América Latina. Buenos Aires: CIESAS \& Prometeo.

Scott, James (1990). Los dominados y el arte de la resistencia. México: Era.

Sen, Amartya (2002). La desigualdad económica. México: FCE.

Subirats, Joan (Dir.) (2004). "Pobreza y exclusión social. Un análisis de la realidad española y europea”. Estudios Sociales 16, Fundación La Caixa, Barcelona. Disponible en: www.estudios.lacaixa.es [Consulta: 14.10.09].

------ (2005). “ ¿Es el territorio urbano una variable significativa en los procesos de exclusión e inclusión social?". En X Congreso Internacional del CLAD sobre la Reforma del Estado y de la Administración Pública. Santiago, Chile, 18-21 de octubre. Disponible en: www.clad.org.ve/fulltext/0053001.pdf [Consulta: 22.10.09].

Tezanos, José (1999). Introducción. Tendencias de dualización y exclusión social en las sociedades tecnológicas avanzadas. Un marco para el análisis. En J. Tezanos (ed.), Tendencias en desigualdad y exclusión social. Tercer foro sobre tendencias sociales, Editorial Sistema: Madrid.

------ (2002). “Desigualdad y exclusión social en las sociedades tecnológicas”. En Revista del Ministerio del Trabajo y Asuntos Sociales 35, Madrid. Disponible en: http://www.mtas.es/es/publica/revista/numeros/35/estudio2.pdf [Consulta: 22.10.09].

Thompson, Edward (1971). Costumbres en común. Barcelona: Crítica. 
Valenzuela, Blas (2007). Economías étnicas en metrópolis multiculturales. Empresarialidad sinaloense en el sur de California. México: Plaza \& Valdés.

Vélez-Ibáñez, Carlos (1983). Lazos de confianza. Los sistemas culturales y económicos de crédito en las poblaciones de los Estados Unidos y México. México: FCE.

Warman, Arturo (2003). Los indios mexicanos en el umbral del milenio. México: FCE.

Weber, Max (1904). La ciudad. Madrid: La Piqueta.

(1922). Economía y sociedad. I. Teoría de la organización social. México: FCE.

Wirth, Louis (1938). “El urbanismo como forma de vida”. En M. FernándezMartorell (Ed.), Leer la ciudad. Barcelona: Icaria. 